\title{
Salivary glucose concentration exhibits threshold kinetics in normal-weight, overweight, and obese children
}

This article was published in the following Dove Press journal:

Diabetes, Metabolic Syndrome and Obesity: Targets and Therapy

17 December 2014

Number of times this article has been viewed

\author{
Mor-Li Hartman' \\ J Max Goodson' \\ Roula Barake ${ }^{2}$ \\ Osama Alsmadi ${ }^{3}$ \\ Sabiha Al-Mutawa ${ }^{4}$ \\ Jitendra Ariga ${ }^{4}$ \\ Pramod Soparkar ${ }^{1}$ \\ Jawad Behbehani ${ }^{5}$ \\ Kazem Behbehani ${ }^{6}$ \\ Francine Welty ${ }^{7}$ \\ 'Department of Applied Oral Sciences, \\ The Forsyth Institute, Cambridge, MA, \\ USA $;{ }^{2}$ Department of Nutrition, The \\ Dasman Diabetes Institute, Dasman, \\ Kuwait; ${ }^{3}$ Genome Center, The Dasman \\ Diabetes Institute, Dasman, Kuwait; \\ ${ }^{4}$ Ministry of Health, Kuwait City, \\ Kuwait; ${ }^{5}$ Faculty of Dentistry, Kuwait \\ University, Kuwait City, Kuwait; ${ }^{6}$ The \\ Dasman Diabetes Institute, Dasman, \\ Kuwait; ${ }^{7}$ Division of Cardiology, Beth \\ Israel Deaconess Medical Center. \\ Boston, MA, USA
}

Correspondence: J Max Goodson The Forsyth Institute, 245 First Street, Cambridge, MA 02142, USA

$\mathrm{Tel}+\mathrm{I} 6178928266$

Fax + I 6172624021

Email mgoodson@forsyth.org
Background: Metabolic syndrome in childhood predicts the development of cardiovascular disease and type 2 diabetes (T2D) in adulthood. Testing for features of metabolic syndrome, such as fasting plasma glucose concentration, requires blood sampling which can be difficult in children. Here we evaluated salivary glucose concentration as a surrogate measurement for plasma glucose concentration in 11-year-old US children.

Methods: Children from Portland, Maine, and Cambridge, Massachusetts, with a mean age of 10.6 \pm 0.2 years provided 6-hour fasting samples of both blood and whole saliva. Salivary glucose levels were measured with a high-sensitivity assay (sensitivity $=0.002 \mathrm{mg} / \mathrm{dL}$ ). Plasma glucose levels were determined by a commercial clinical laboratory. Blood pressure, salivary flow rate, height, and weight were also measured.

Results: Of the 65 children enrolled, there were two underweight children (3.1\%), 30 normal-weight children (46.2\%), 12 overweight children (18.4\%), and 21 obese children (32.3\%). The mean overall glucose concentrations were $0.11 \pm 0.02 \mathrm{mg} / \mathrm{dL}$ in saliva and $86.3 \pm 0.8 \mathrm{mg} / \mathrm{dL}$ in plasma, and these did not differ significantly by body-weight groups. By regression analysis, the plasma concentration equaled 13.5 times the saliva concentration, with a threshold level of $84.8 \mathrm{mg} / \mathrm{dL}$. Salivary glucose values less than threshold plasma concentration were essentially zero. Diagnostic analysis indicated a positive predictive value of $50 \%$, a negative predictive value of $90 \%$, and a sensitivity and specificity both of approximately $75 \%$. The salivary glucose concentration did not vary with saliva flow rate.

Conclusion: Taking into account the threshold response characteristics of the salivary glucose concentration response, these results suggest that testing salivary glucose levels may be useful as a screening assay for high fasting plasma glucose levels. The low false positive value is important to assure a low fraction of missed diagnoses.

Keywords: saliva, salivary glucose, plasma glucose, children

\section{Introduction}

In adults, metabolic syndrome is defined as a cluster of cardiovascular risk factors, including hypertension, altered glucose metabolism, dyslipidemia, and abdominal obesity, that are associated with an increased risk of atherosclerotic cardiovascular disease and type 2 diabetes (T2D). Metabolic syndrome has also been associated with the development of other chronic diseases, including hyperandrogenism, polycystic ovary syndrome, hepatic steatosis, and nonalcoholic fatty liver disease, among others. ${ }^{1}$ Although, historically, metabolic syndrome was not considered a pediatric disorder, the alarming rise of obesity among children and adolescents worldwide ${ }^{2}$ has been met with a corresponding rise in the prevalence of metabolic syndrome in these age groups. ${ }^{3}$ As with adults, several longitudinal studies have demonstrated that 
metabolic syndrome in childhood predicts the development of cardiovascular disease and T2D in adulthood, ${ }^{4-6}$ with an increased risk of early mortality. ${ }^{7}$

There has been much disagreement in the field about how to define metabolic syndrome in children, and several definitions have been proposed by various research groups and expert consensus panels. Notably, all contain some common features, including an obesity variable (waist circumference or body mass index [BMI]), dyslipidemia variables (elevated triglycerides and low high-density lipoprotein cholesterol), elevated blood pressure, and a variable representing glucose metabolism (impaired fasting glucose or impaired glucose tolerance). ${ }^{8-10}$ As some of these variables require the collection of blood samples for testing, which can be difficult in children, there has been interest in the development of non-invasive methods for assessing metabolic disease risk factors. ${ }^{11}$ Because many molecules found in plasma are also found in saliva, the ease and noninvasive nature of saliva sampling is attractive.

One factor that has been considered for salivary analysis is fasting glucose, assuming that the level of salivary glucose might be used as a surrogate measurement for the level in plasma. ${ }^{12}$ This approach has been tested in patients with T2D, with several studies reporting a significant correlation between fasting blood glucose and fasting salivary glucose levels. ${ }^{13-16}$ Considerable controversy has surrounded this approach when applied to patients without T2D, however, since some studies have found measureable salivary glucose levels in healthy controls ${ }^{13,14}$ while others have not. ${ }^{15,16}$ To our knowledge, no studies have been performed evaluating the utility of salivary glucose levels as a surrogate marker for plasma glucose levels in children and adolescents at risk for metabolic syndrome. Therefore, we evaluated the utility of salivary glucose analysis as a possible screening test for fasting hyperglycemia in children by comparing the glucose levels in salivary and blood samples given by 11-year-old US children who were either normal weight, overweight, or obese.

\section{Patients and methods \\ Patients}

Children of both sexes between the ages of 10 and 11 years were recruited by advertisement in the Cambridge, Massachusetts, and Portland, Maine, areas from February 2011 to September 2011 using a protocol reviewed and approved by the Forsyth Institutional Review Board. Only children with extreme disease conditions, such as immuno-deficiencies, cancer, or serious behavioral disorders, were excluded. The target study size was set at 75 children based on obtaining approximately 25 children in each of the body weight categories of normal, overweight, and obese. Both informed consent and participant assent were obtained from the parents/guardians of each child and from the child.

\section{Assessments}

All assessments were conducted by trained examiners. Height was measured by stadiometer and weight was measured by a calibrated bathroom scale. Blood pressure and heart rate were measured after the children had sat quietly for 10 minutes with both feet on the floor, and the measurements were performed using an automated wrist monitor sized appropriately for children. Fitness was measured by a standardized 3-minute step test ${ }^{17}$ where the change in heart rate was measured by a pulse oximetry probe (RAD-57, Masimo Corporation, Irvine, CA, USA) applied to the finger.

\section{Saliva collection}

Saliva was collected under 6-hour fasting conditions by dental hygienists. Each child was given a wrist label with a printed number and a dated, labeled, sterile, $15 \mathrm{~mL}$ plastic screw-top centrifuge tube (Product \#430791, Corning Incorporated Life Sciences, Tewksbury, MA, USA) with the same number as the wrist band. Before saliva collection, each child rinsed with and swallowed $15 \mathrm{~mL}$ of water. Whole saliva (approximately $3 \mathrm{~mL}$ ) was collected by having the child drool, not spit, into the screw-top tube. Tubes were kept on ice while saliva was allowed to accumulate in the child's mouth. A monitor recorded the start time of the saliva collection, verified that 3 $\mathrm{mL}$ was collected from each child, recorded the stop time for each child, assured that the screw-cap was securely applied to the tube, and transferred the labeled tube to an ice bath for temporary storage. The average collection time was $7.68 \pm 4.8$ minutes (mean \pm standard error of the mean).

\section{Salivary glucose analysis}

Saliva samples were weighed and then centrifuged at 2,800 rpm at $4^{\circ} \mathrm{C}$ for 20 minutes. Two $1 \mathrm{~mL}$ aliquots of the supernatants were transferred to screw-cap storage tubes and maintained frozen at $-80^{\circ} \mathrm{C}$ until assayed. For the glucose analysis, the glucose oxidase method using fluorescent emission of the dye (Glucose Colorimetric/Fluorometric Assay Kit \#K606-100, BioVision, Inc., Mountain View, CA, USA) measured at Ex/Em $-535 / 590 \mathrm{~nm}$ was adapted to work on a Tecan Freedom $\mathrm{EVO}^{\circledR} 150$ robotic processor with an 8-channel liquid handling arm (Tecan Group Ltd, Männedorf, Switzerland). The fluorescence was measured by a 
spectrophotometer (Infinite ${ }^{\circledR} 200$ Pro, Tecan Group Ltd) using reverse 96 -well plate reading mode. The 3-sigma detection limit of the glucose assay was $0.002 \mathrm{mg} / \mathrm{dL}$. Thirty microliters of saliva supernatant were assayed for each sample. Standards of $0.12,0.24,0.48$, and $0.96 \mathrm{mg} / \mathrm{dL}$ were assayed in triplicate on each run. Coefficient of variation measurements on the same day and over a period of 98 days are found in Table 1. These data indicate that variation is increased for more dilute samples and ranges from 23 to 101 depending on glucose concentration. Coefficient of variation values reported for saliva sample analysis are often higher than those reported for serum analysis of the same biochemical, ${ }^{18}$ possibly due to characteristics unique to saliva that increase measurement variability (viscosity, propensity to form bubbles, etc).

\section{Plasma glucose analysis}

Two milliliters of blood were obtained by venipuncture from the antecubital fossa under 6-hour fasting conditions and were collected into potassium oxalate/sodium fluoride (grey top) tubes. Collected blood samples were centrifuged at 2,800 rpm for 20 minutes. Two $0.5 \mathrm{~mL}$ plasma aliquots were dispensed into labeled, sterile, $1.8 \mathrm{~mL}$ screw-cap vials (Nunc $^{\circledR}$ CryoTubes $^{\circledR} \# 363401$, Thermo Fisher Scientific Inc., Asheville, NC, USA) which were stored at $-80^{\circ} \mathrm{C}$ until assayed. Plasma glucose levels were measured by a commercial clinical laboratory (test code 484, Quest Diagnostics Inc., Cambridge, MA, USA).

\section{Statistical and analytical}

BMI was calculated by dividing body weight in kilograms by height in meters squared. Body weight categories were determined from BMI percentile using The Centers for Disease Control software as follows: underweight, $<5$ th percentile; normal weight, 5 th-84th percentile; overweight, 85th-94th percentile; obese $\geq 95$ th percentile. ${ }^{19}$ The saliva flow rate was computed by dividing the tarred weight of the saliva collection tube by the difference in the start and stop collection times in hours. The salivary glucose excretion rate

Table I Within- and between-day CV measurements of glucose in saliva samples

\begin{tabular}{lll}
\hline $\begin{array}{l}\text { Glucose concentration } \\
(\mathbf{m g} / \mathbf{d L})\end{array}$ & $\begin{array}{l}\text { Within-day } \\
\mathbf{C V}^{\mathbf{a}}\end{array}$ & $\begin{array}{l}\text { Between-day } \\
\mathbf{C V}^{\mathbf{b}}\end{array}$ \\
\hline$\geq 0.2$ & 22.9 & 27.3 \\
$0.2<$ concentration $>0.1$ & 54.6 & 41.0 \\
$\leq 0.1$ & $10 \mathrm{I} .1$ & 46.1 \\
\hline
\end{tabular}

Notes: a Duplicate measurements on one day (18 samples); b three measurements over 98 days (47 samples).

Abbreviation: CV, coefficient of variation. was calculated by multiplying the salivary flow rate by the saliva glucose concentration. Associations between saliva glucose values and plasma values were investigated through linear regression analyses. The analysis of significant differences between parameters related to population characteristics was by analysis of variance. Significant pairwise differences were determined by post hoc analysis using Tukey's test.

\section{Results}

\section{Patients and demographics}

A total of 65 children were enrolled, of which $63 \%$ were male (Table 2). The mean overall age of the children was 10.6 \pm 0.2 years old, with obese and overweight children being slightly older. There were two underweight children (3.1\%), 30 normal-weight children (46.2\%), 12 overweight children (18.4\%), and 21 obese children (32.3\%). The number of underweight children in the group was too small to be meaningful for statistical analyses. Both diastolic and systolic blood pressure tended to be higher in obese children relative to normalweight children $(124 / 69 \mathrm{mmHg}$ versus $116 / 67 \mathrm{mmHg}$ ), but neither value varied significantly. The mean overall fasting plasma glucose level was $86.3 \mathrm{mg} / \mathrm{dL}$, and did not differ significantly between body-weight groups.

\section{Salivary glucose concentration is not functionally related to saliva flow rate}

The mean saliva collection time was $7.68 \pm 4.8 \mathrm{~min}$ (range, $2-28 \mathrm{~min}$ ). The average volume collected was $3.93 \pm 0.92 \mathrm{~mL}$ (range, 3-8 mL). The mean overall fasting salivary glucose level was $0.11 \pm 0.02 \mathrm{mg} / \mathrm{dL}$, and the mean salivary glucose excretion rate was $41.2 \pm 8 \mu \mathrm{g} / \mathrm{h}$, with no statistically significant differences seen between children in the different body weight categories. The salivary flow rate was $40.1 \pm 19.3 \mathrm{~mL} / \mathrm{h}$ (range $7-95 \mathrm{~mL} / \mathrm{h}$ ), which was again not statistically significantly different between body weight categories. By regression analysis, the saliva glucose concentration did not appear to be functionally related to saliva flow rate (Figure 1).

\section{Salivary glucose levels exhibit threshold kinetics}

There was a significant association between plasma and salivary glucose levels, although there was considerable variability (Figure 2A). The functional relationship between the plasma and salivary glucose concentrations clearly exhibited a threshold. Plasma glucose concentrations less than the threshold value of $84.8 \mathrm{mg} / \mathrm{dL}$ produced unmeasurable salivary glucose levels. At plasma concentrations greater than $84.8 \mathrm{mg} / \mathrm{dL}$, the plasma glucose concentration increased 
Table 2 Population characteristics of the enrolled children

\begin{tabular}{|c|c|c|c|c|c|}
\hline & \multicolumn{4}{|c|}{ Body weight category } & \multirow[t]{2}{*}{ Overall } \\
\hline & Underweight & Normal weight & Overweight & Obese & \\
\hline $\mathrm{N}$ & 2 & 30 & 12 & 21 & 65 \\
\hline Age $(y)$ & $9.8 \pm 1.4$ & $10.0 \pm 0.2^{\mathrm{a}}$ & $11.2 \pm 0.5$ & $11.2 \pm 0.4^{\mathrm{a}}$ & $10.6 \pm 0.2^{*}$ \\
\hline Sex (number of males [\%]) & $\mathrm{I}(50)$ & $18(60)$ & $7(58.3)$ & $15(7 \mid .4)$ & $4 I(63.0)$ \\
\hline Plasma glucose (mg/dL) & $89.5 \pm 10.5$ & $86.5 \pm 1.2$ & $84.8 \pm 1.9$ & $86.5 \pm 1.5$ & $86.3 \pm 0.8$ \\
\hline Salivary glucose (mg/dL) & $0.29 \pm 0.04$ & $0.10 \pm 0.02$ & $0.11 \pm 0.03$ & $0.09 \pm 0.04$ & $0.11 \pm 0.02$ \\
\hline Glucose excretion $(\mu g / h)$ & $88.1 \pm 20.4$ & $42.6 \pm 10.9$ & $54.3 \pm 24.6$ & $27.9 \pm 13.7$ & $41.2 \pm 8.0$ \\
\hline Saliva flow rate $(\mathrm{mL} / \mathrm{h})$ & $29.6 \pm 2.6$ & $40.5 \pm 3.4$ & $44.2 \pm 5.5$ & $38.3 \pm 4.8$ & $40.1 \pm 2.4$ \\
\hline Diastolic blood pressure $(\mathrm{mmHg})$ & $69 \pm 2$ & $67 \pm 1$ & $68 \pm 2$ & $69 \pm 2$ & $69 \pm 1$ \\
\hline Systolic blood pressure (mmHg) & $119 \pm 2$ & $116 \pm 2$ & $|2| \pm 3$ & $124 \pm 2$ & $120 \pm I$ \\
\hline BMI & $13.5 \pm 0.3^{\mathrm{ab}}$ & $17.2 \pm 0.3^{\mathrm{cd}}$ & $22.2 \pm 0.6^{\text {ace }}$ & $28.5 \pm 1.2^{\text {bde }}$ & $21.7 \pm 0.8^{*}$ \\
\hline
\end{tabular}

Notes: *Model $P<0.05$. Tabulated ranges are mean \pm SEM. Overall differences between body weight categories were tested by ANOVA. Significant pairwise differences were determined by post hoc analysis using Tukey's test. Values with the same superscript letter within each row differed at $P<0.05$.

Abbreviations: ANOVA, analysis of variance; BMI, body mass index; SEM, standard error of the mean.

at a rate of 13.5 times the saliva glucose concentration. If positive salivary glucose values occur only at plasma values greater than zero, a threshold is implied. Mathematically, this occurs when the y-intercept assumes a large value rather than zero.

\section{Salivary glucose levels have a high negative predictive value}

The diagnostic potential of salivary glucose to predict plasma glucose is illustrated in Figure 2B. Diagnostic sensitivity and specificity were $75 \%$ and $76 \%$ respectively, but the false-positive rate was much higher than the falsenegative rate, and the false-positive rate was equal to the truepositive rate. As such, salivary glucose levels would correctly identify only $50 \%$ of children with high plasma glucose levels. Conversely, the false-negative rate was small relative

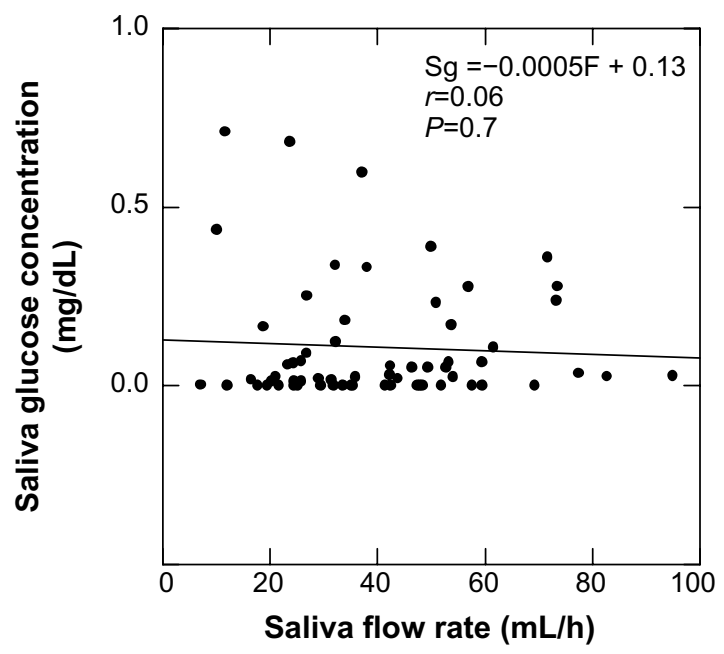

Figure I Saliva glucose concentration $(\mathrm{Sg})$ as a function of salivary flow rate $(\mathrm{F})$ by regression analysis. to the true-negative rate, so the probability of a child having a high plasma glucose level with a low salivary glucose level $(\leq 0.06 \mathrm{mg} / \mathrm{dL})$ is very low, and the negative predictive value is high (90\%). Figure $2 \mathrm{C}$ illustrates the receiver operating curve with an area under the curve measurement of 0.78 , an indication of good but not excellent accuracy of the salivary glucose method.

\section{Discussion}

Our investigation into the correlation between salivary and plasma glucose levels in children has been prompted by the need for a non-invasive method to determine the occurrence of hyperglycemia as part of the syndrome describing metabolic disease. ${ }^{9}$ In this study, we compared fasting plasma and salivary glucose concentrations in a sample of 65 US children with a mean age of $10.6 \pm 0.2$ years and found that salivary glucose levels exhibit threshold kinetics. While plasma glucose concentrations less than the threshold value of $84.8 \mathrm{mg} / \mathrm{dL}$ produced unmeasurable salivary glucose levels, plasma concentrations over the threshold appeared to produce a linear rise in salivary glucose levels. It is well-known that hyperglycemia (fasting blood glucose $\geq 100 \mathrm{mg} / \mathrm{dL}$ ) occurs in children at a frequency of up to $10 \%,,^{20,21}$ and the development of hyperglycemia is clearly an important step in the progression of metabolic syndrome to T2D. ${ }^{22}$ Our data suggest that salivary glucose testing may be a potentially useful screening tool for metabolic syndrome in children. While salivary glucose testing may miss up to $50 \%$ of children with high plasma glucose levels, it would almost certainly identify those children who do not have high plasma glucose levels, sparing these children from further invasive testing. This method also has the advantage of being free of adverse reactions, compared to an adverse reaction incidence of $2 \%$ 

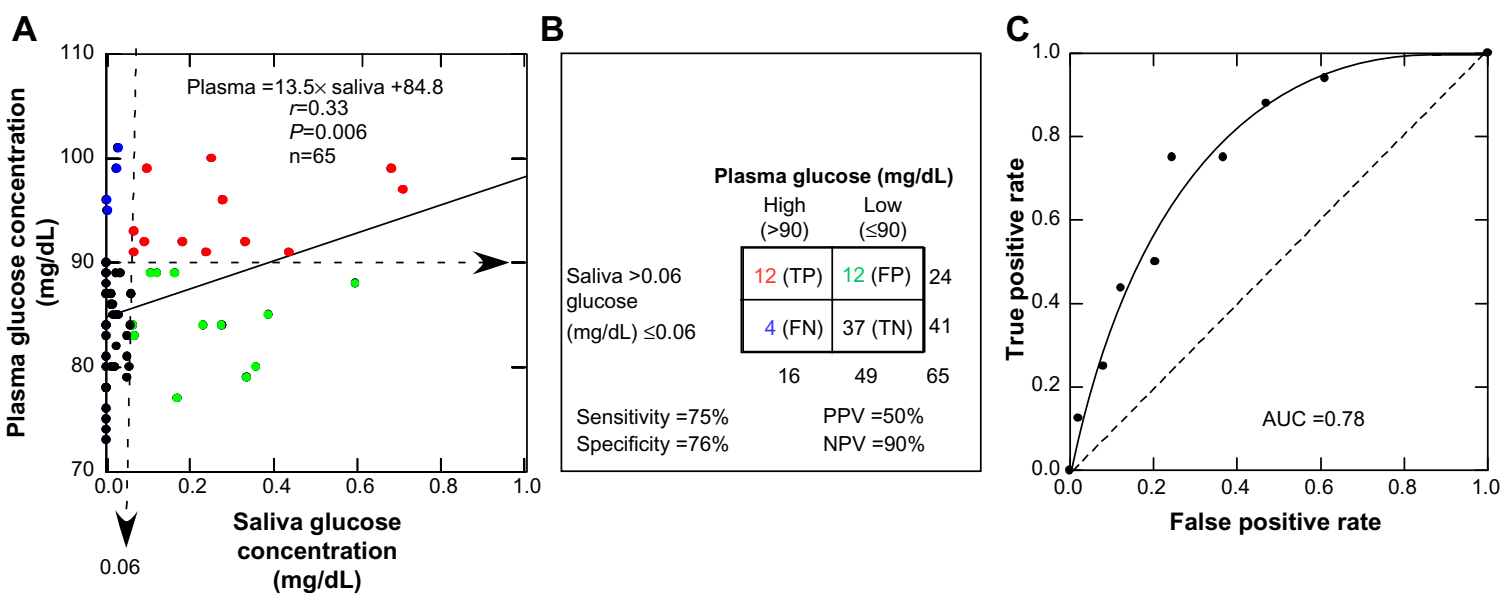

Figure 2 Plasma glucose concentration as a function of salivary glucose concentration.

Notes: (A) Regression analysis of samples from all of the children in the study (mean age $10.6 \pm 0.2$ y). (B) $2 \times 2$ analysis of the diagnostic capability of salivary glucose testing to identify children with high plasma glucose levels ( $>90 \mathrm{mg} / \mathrm{dL}$ ) using a value of $0.06 \mathrm{mg} / \mathrm{dL}$ in saliva as an identification criterion. (C) Receiver operating curve indicating an area AUC measurement of 0.78 .

Abbreviations: TP, true positive (red); FP, false positive (green); TN, true negative (black), FN, false negative (blue); PPV, positive predictive value; NPV, negative predictive value; $A \cup C$, area under the curve.

and a loss-of-consciousness incidence of $0.3 \%$ reported in a study involving venous sampling in children. ${ }^{23}$

The identification of a threshold response in human salivary glucose concentration is intriguing. The phenomenon of a salivary glucose concentration threshold was first reported by investigators studying canine saliva. ${ }^{24}$ As early as 1891 , these investigators reported that glucose does not normally appear in the saliva of dogs, but when the blood glucose concentration was elevated by intravenous infusion to approximately $512 \mathrm{mg} / \mathrm{dL}$, glucose began to appear in saliva at a level proportional to blood levels. Our data, as well as those of others, indicate that salivary glucose in humans also exhibits a threshold response (Table 3). ${ }^{14,15,25,26}$ The data suggest that the human salivary glucose threshold is in the range of 84.8 to $136.8 \mathrm{mg} / \mathrm{dL}$ and that the slope is in the range of 6.4 to 55.3. It is clear that these values may vary depending on the glandular source of saliva, the method of collection, the population characteristics, and even the individual subject. This latter point was made elegantly in a study that continuously measured salivary and blood glucose levels in six normal-weight adult subjects following the oral administration of $75 \mathrm{~g}$ of glucose. ${ }^{26}$ Considerable variability

Table 3 Representative studies that provide analytical data for evaluating the relationship between salivary glucose and blood glucose concentrations as a threshold response

\begin{tabular}{|c|c|c|c|c|c|c|c|}
\hline Study & Species & Sample & $\begin{array}{l}\text { Threshold } \\
\text { (mg/dL) }\end{array}$ & Slope & $r$ & $P$-value & Population \\
\hline Forbat et al $(1981)^{25}$ & Human & Parotid saliva $^{\mathrm{a}}$ & 136.8 & 6.4 & 0.20 & 0.38 & 20 diabetic adults $^{\mathrm{b}}$ \\
\hline Amer et al $(2001)^{15}$ & Human & Whole saliva & 107.0 & 12.7 & 0.78 & $<0.05$ & I 35 diabetic adults \\
\hline Abikshyeet et al $(2012)^{14}$ & Human & Whole saliva & 99.7 & 13.0 & 0.77 & $<0.01$ & 106 diabetic adults \\
\hline Current study & Human & Whole saliva & 84.8 & 13.5 & 0.33 & 0.006 & 65, II-year-old children \\
\hline \multicolumn{8}{|l|}{ Yamaguchi et al $(1998)^{26}$} \\
\hline$A$ & Human & Submaxillary + & 110 & 22.4 & & & 6 healthy adults $(A-F)^{c}$ \\
\hline B & & sublingual saliva & 68 & 87.1 & & & \\
\hline C & & & 104 & 13.8 & & & \\
\hline$D$ & & & 60 & III.I & & & \\
\hline E & & & 105 & 46.7 & & & \\
\hline $\mathrm{F}$ & & & 88 & 51.0 & & & \\
\hline Average & & & $89.1 \pm 8.6$ & $55.3 \pm 15.3$ & & & \\
\hline Hayford et al $(1983)^{27}$ & Human & Urine & 152.7 & 47.4 & 0.80 & & 24 diabetic adults \\
\hline Langley et al $(1958)^{24}$ & Dogs & Parotid saliva & 512.0 & & & & $10-12 \mathrm{~kg}$ dogs \\
\hline
\end{tabular}

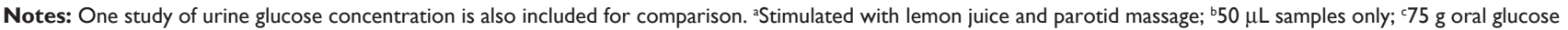
tolerance test. 
existed between individuals in both the salivary threshold and the slope of the blood: saliva concentration response function. Therefore, if salivary glucose testing were to be adopted clinically, a standardized protocol for fasting, collection, and analysis would need to be established.

A threshold plasma level for the appearance of glucose in saliva evokes the relationship between plasma and renal glucose concentrations. The data in Table 3 include an estimated threshold response in urine of $152.7 \mathrm{mg} / \mathrm{dL},{ }^{27}$ suggesting that salivary glands exhibit a lower glucose threshold than does the kidney. There are several similarities between the kidney and salivary glands. Morphologic and immunologic similarities between the striated ducts of the salivary gland and the kidney have been demonstrated. For example, in animal models, the $\mathrm{Na}(+)$-dependent glucose co-transporter SGLT1 is found in both the kidney and in the acinar and ductal cells of salivary glands. ${ }^{28-31}$ As with urine in the kidney, the formation of saliva has been proposed to be a two-stage process. ${ }^{32,33}$ In this model, saliva is initially formed by salivary acinar cells as a primary fluid with a small-molecule composition similar to that of plasma. The primary fluid is then modified by the salivary gland system that reabsorbs sodium and glucose until the resulting hypotonic glucose-depleted (relative to plasma) oral saliva is secreted into the mouth. It seems possible that the salivary glucose threshold could occur by a mechanism similar to that found in the kidney.

Recognition that salivary glucose exhibits a threshold response can aid in the interpretation of the diagnostic potential of salivary glucose. First, it means that salivary glucose levels are likely to be useful only for diagnosis of high glucose conditions. As such, salivary glucose could still prove a useful indicator of pathological status - a lack of salivary glucose would be good news for the patient with diabetes! Yet, we must contend with the issue of false-negatives. In our study, we found many readings along the axis of zero for salivary glucose concentration (Figure 2A), which may represent children with a higher-than-average salivary glucose concentration threshold which had not yet been exceeded. It is commonly reported in the salivary glucose literature that there is a significant correlation between plasma and salivary glucose levels under conditions in which hyperglycemia is expected, such as in subjects with uncontrolled diabetes, ${ }^{34}$ but that there is little or no correlation under conditions where hyperglycemia may not be expected, such as in healthy subjects and in patients with controlled diabetes. ${ }^{16}$ This fact becomes understandable if blood glucose levels are at or below the value of the salivary glucose concentration threshold. Secondly, we do not know what parameters modulate the salivary glucose concentration threshold in humans. The original research in dogs has shown that an intravenous infusion of insulin increases the threshold level for the salivary glucose concentration. ${ }^{24}$ Whatever mechanisms control the salivary glucose concentration threshold, it seems likely that salivary glucose concentration does result from simple passive diffusion from plasma. Further studies will be needed to clarify these issues.

\section{Conclusion}

The recognition of threshold kinetics in salivary glucose concentration measurements suggests that if children have measurable salivary glucose levels $\geq 0.06 \mathrm{mg} / \mathrm{dL}$, there is a significant probability that they have high plasma glucose levels. If they have salivary glucose levels above $1 \mathrm{mg} / \mathrm{dL}$, then they are likely to be hyperglycemic (plasma levels $>100 \mathrm{mg} / \mathrm{dL}$ ), although this criterion could be greatly modified in certain defined clinical conditions and carries a low positive predictive value (positive predictive value $=50 \%$ ). As a screening diagnostic, however, low positive predictive value is acceptable, since the test would ultimately be used as a trigger to seek professional confirmation. Indeed, a high false-negative rate, which is not the case here, would be the worst case scenario, since it would inappropriately assure the absence of high plasma glucose levels. In our study, the probability that a child would not have a high plasma glucose level if the saliva glucose is low ( $\leq 0.06 \mathrm{mg} / \mathrm{dL}$ ), the negative predictive value is $90 \%$. Although our methods are designed for research purposes, by this analysis, saliva glucose appears to have reasonable characteristics to serve as a screening diagnostic for high plasma glucose in children.

\section{Acknowledgments}

We acknowledge the help of T Yaskell and C Floros in the collection of samples and J Vargas for saliva assays. We acknowledge the aid of M Tavares, M Cugini, and H Hasturk in the conduct of the clinical examinations and conduct of the clinical study. We also acknowledge the assistance of New England Survey Systems of Brookline Massachusetts for aid in database preparation. We thank Jillian Lokere, MS, for editorial assistance in preparing the manuscript.

\section{Author contributions}

Authorship of this manuscript is equally shared between JMG, $\mathrm{FW}$, and $\mathrm{MH}$. Participants in the experimental design included RB, OA, SA, JA, PS, JB, and KB. All authors contributed toward data analysis, drafting and revising the paper and agree to be accountable for all aspects of the work. 


\section{Disclosure}

The authors report no conflicts of interest.

\section{References}

1. Weiss R, Bremer AA, Lustig RH. What is metabolic syndrome, and why are children getting it? Ann NY Acad Sci. 2013;1281:123-140.

2. Guidelines for the acceptance of peroxide-containing oral hygiene products. American Dental Association Council on Dental Therapeutics. J Am Dent Assoc. 1994;125(8):1140-1142.

3. Camhi SM, Katzmarzyk PT. Prevalence of cardiometabolic risk factor clustering and body mass index in adolescents. $J$ Pediatr. 2011;159(2):303-307.

4. Franks PW, Hanson RL, Knowler WC, et al. Childhood predictors of young-onset type 2 diabetes. Diabetes. 2007;56(12):2964-2972.

5. Schubert CM, Sun SS, Burns TL, Morrison JA, Huang TT. Predictive ability of childhood metabolic components for adult metabolic syndrome and type 2 diabetes. J Pediatr. 2009;155(3):S6. e1-e7.

6. Magnussen CG, Koskinen J, Chen W, et al. Pediatric metabolic syndrome predicts adulthood metabolic syndrome, subclinical atherosclerosis, and type 2 diabetes mellitus but is no better than body mass index alone: the Bogalusa Heart Study and the Cardiovascular Risk in Young Finns Study. Circulation. 2010;122(16):1604-1611.

7. Franks PW, Hanson RL, KnowlerWC, Sievers ML, BennettPH, LookerHC. Childhood obesity, other cardiovascular risk factors, and premature death. N Engl J Med. 2010;362(6):485-493.

8. Cook MD, Weitzman M, Auinger P, Nguyen M, Dietz WH. Prevalence of a metabolic syndrome phenotype in adolescents: findings from the third National Health and Nutrition Examination Survey, 1988-1994. Arch Pediatr Adolesc Med. 2003;157(8):821-827.

9. Zimmet P, Alberti KG, Kaufman F, et al. The metabolic syndrome in children and adolescents - an IDF consensus report. Pediatr Diabetes. 2007;8(5):299-306.

10. Goodman E, Daniels SR, Morrison JA, Huang B, Dolan LM. Contrasting prevalence of and demographic disparities in the World Health Organization and National Cholesterol Education Program Adult Treatment Panel III definitions of metabolic syndrome among adolescents. J. Pediatr. 2004;145(4):445-451.

11. Morandi A, Maffeis C. Predictors of metabolic risk in childhood obesity. Horm Res Paediatr. 2014;82(1):3-11.

12. Shannon IL, Prigmore JR, Brooks RA. Glucose concentrations in parotid fluid and blood serum following intravenous glucose loading. Oral Surg Oral Med Oral Pathol. 1960;13:1010-1012.

13. Satish BN, Srikala P, Maharudrappa B, Awanti SM, Kumar P, Hugar D. Saliva: A tool in assessing glucose levels in Diabetes Mellitus. $J$ Int Oral Health. 2014;6(2):114-117.

14. Abikshyeet P, Ramesh V, Oza N. Glucose estimation in the salivary secretion of diabetes mellitus patients. Diabetes Metab Syndr Obes. 2012;5:149-154.

15. Amer S, Yousuf M, Siddqiui PQ, Alam J. Salivary glucose concentrations in patients with diabetes mellitus - a minimally invasive technique for monitoring blood glucose levels. Pak J Pharm Sci. 2001;14(1):33-37.

16. Panchbhai AS. Correlation of salivary glucose level with blood glucose level in diabetes mellitus. J Oral Maxillofac Res. 2012;3(3):e3.
17. Suriano K, Curran J, Byrne SM, Jones TW, Davis EA. Fatness, fitness, and increased cardiovascular risk in young children. J Pediatr. 2010;157(4):552-558.

18. Browne RW, Kantarci A, LaMonte MJ, et al. Performance of multiplex cytokine assays in serum and saliva among community-dwelling postmenopausal women. PloS One. 2013;8(4):e59498.

19. cdc.gov [homepage on the Internet]. Child and teen BMI calculator. Centers for Disease Control and Prevention; 2012. Available from: http://nccd.cdc.gov/dnpabmi/. Accessed September 22, 2014.

20. Park J, Hilmers DC, Mendoza JA, Stuff JE, Liu Y, Nicklas TA. Prevalence of metabolic syndrome and obesity in adolescents aged 12 to 19 years: comparison between the United States and Korea. J Korean Med Sci. 2010;25(1):75-82.

21. Kranz S, Mahood LJ, Wagstaff DA. Diagnostic criteria patterns of US children with Metabolic Syndrome: NHANES 1999-2002. Nutr J. 2007;6:38.

22. Kuzuya M, Ando F, Iguchi A, Shimokata H. Age-specific change of prevalence of metabolic syndrome: longitudinal observation of large Japanese cohort. Atherosclerosis. 2007;191(2):305-312.

23. HEALTHY Study Group, Foster GD, Linder B, et al. A school-based intervention for diabetes risk reduction. $N$ Engl J Med. 2010;363(5): 443-453.

24. Langley LL, Gunthorpe CH, Beall WA. Salivary glucose threshold. Am J Physiol. 1958;192(3):482-484.

25. Forbat LN, Collins RE, Maskell GK, Sönksen PH. Glucose concentrations in parotid fluid and venous blood of patients attending a diabetic clinic. J R Soc Med. 1981;74(10):725-728.

26. Yamaguchi M, Mitsumori M, Kano Y. Noninvasively measuring blood glucose using saliva. IEEE Eng Med Biol Mag. 1998;17(3):59-63.

27. Hayford JT, Weydert JA, Thompson RG. Validity of urine glucose measurements for estimating plasma glucose concentration. Diabetes Care. 1983;6(1):40-44.

28. Cetik S, Hupkens E, Malaisse WJ, Sener A, Popescu IR. Expression and localization of glucose transporters in rodent submandibular salivary glands. Cell Physiol Biochem. 2014;33(4):1149-1161.

29. Wright EM, Loo DD, Hirayama BA. Biology of human sodium glucose transporters. Physiol Rev. 2011;91(2):733-794.

30. Jurysta C, Nicaise C, Cetik S, Louchami K, Malaisse WJ, Sener A. Glucose transport by acinar cells in rat parotid glands. Cell Physiol Biochem. 2012;29(3-4):325-330.

31. Hussar P, Suuroja T, Hussar U, Haviko T. Transport proteins in rats' renal corpuscle and tubules. Medicina (Kaunas). 2004;40(7):650-656.

32. Thaysen JH, Thorn NA, Schwartz IL. Excretion of sodium, potassium, chloride and carbon dioxide in human parotid saliva. Am J Physiol. 1954;178(1):155-159.

33. Sabino-Silva R, Okamoto MM, David-Silva A, Mori RC, Freitas HS, Machado UF. Increased SGLT1 expression in salivary gland ductal cells correlates with hyposalivation in diabetic and hypertensive rats. Diabetol Metab Syndr. 2013;5(1):64.

34. Englander HR, Jeffay AI, Fuller JB, Chauncey HH. Glucose Concentrations in Blood Plasma and Parotid Saliva of Individuals with and without Diabetes Mellitus. J Dent Res. 1963;42:1246.

Diabetes, Metabolic Syndrome and Obesity: Targets and Therapy

\section{Publish your work in this journal}

Diabetes, Metabolic Syndrome and Obesity: Targets and Therapy is an international, peer-reviewed open-access journal committed to the rapid publication of the latest laboratory and clinical findings in the fields of diabetes, metabolic syndrome and obesity research. Original research, review, case reports, hypothesis formation, expert
Dovepress

opinion and commentaries are all considered for publication. The manuscript management system is completely online and includes a very quick and fair peer-review system, which is all easy to use. Visit $\mathrm{http}: / /$ www.dovepress.com/testimonials.php to read real quotes from published authors. 